\title{
Quality-Control Assessment to Improve the Accuracy of Dynamic Contrast-Enhanced MR Imaging Perfusion
}

W e read with much interest the article by Dr Morales and colleagues published in the May 2018 issue of American Journal of Neuroradiology ${ }^{1}$ in which they showed that T1weighted dynamic contrast-enhanced (DCE) MR imaging might help differentiate atypical hemangiomas from metastatic vertebral lesions.

The authors used a dynamic 2-step approach with a visual assessment of T1 curves and a modelization of the DCE MRI using the extended Tofts 2-compartment pharmacokinetic model, providing quantitative perfusion parameters such as the plasma volume $(\mathrm{Vp})$ and the volume transfer constant $\left(K^{\text {trans }}\right)$. This approach could have been strengthened by the integration of a quality-control assessment of the DCE based on the individual arterial input function (AIF) curves. When an individual AIF is near the mean AIF of the population, it might be integrated into the simplified visual assessment of the curves. Alternatively, when an individual's AIF is far from the mean AIF of the population, 2 approaches might be used to provide more accurate quantitative data: the first one using only the pharmacokinetic model approach to analyze the quantitative parameters; the second correcting data with a B-spline-based model-independent deconvolution to obtain a renormalized tissular kinetic. ${ }^{2}$ This latter approach gathers more accurate quantitative parameters.

The authors used the $K^{\text {trans }}$ to demonstrate preservation of permeability in cases of atypical hemangiomas with an abnormally elevated Vp. This approach should be used cautiously because the $K^{\text {trans }}$ method of calculation includes both perfusion and permeability-related phenomena, leading to a possible misinterpretation of the parameters, even when data are accurately fitted. ${ }^{3}$ The use of the extravascular and extracellular volume fraction (Ve) provided by the extended Tofts model, or, even better, the use of a more comprehensive and complex model such as the 2-compartment exchange or $2 \mathrm{CX}$ model ${ }^{4}$ can better quantify the permeability measurement.

It would be very interesting to perform a second segmentation by a second reader, if possible an inexperienced one, to evaluate the inter- and intraobserver variability and to reinforce the findings of the study and support its use in clinical practice.

Besides this feedback, our colleagues' very interesting work could considerably help radiologists before and during diagnosis and lead to changes in patient management, reducing biopsies, additional imaging, and patient anxiety in persons with atypical hemangiomas.

Disclosures: Julien Savatovsky—UNRELATED: Consultancy: IRIS Institut de Recherche International Servier; Grants/Grants Pending: ANRS Agence Nationale pour la Recherche Scientifique*; Payment for Lectures Including Service on Speakers Bureaus: Bayer Healthcare, Philips Healthcare, Medtronic, Biogen, Sanofi; Travel/ Accommodations/Meeting Expenses Unrelated to Activities Listed: Philips Healthcare, GE Healthcare, Bayer Healthcare. *Money paid to the institution.

\section{REFERENCES}

1. Morales KA, Arevalo-Perez J, Peck KK, et al. Differentiating atypical hemangiomas and metastatic vertebral lesions: the role of T1weighted dynamic contrast-enhanced MRI. AJNR Am J Neuroradiol 2018;39:968-73 CrossRef Medline

2. Jerosch-Herold M, Swingen C, Seethamraju RT. Myocardial blood flow quantification with MRI by model-independent deconvolution. Med Phys 2002;29:886-97 CrossRef Medline

3. Sourbron SP, Buckley DL. Classic models for dynamic contrast-enhanced MRI. NMR Biomed 2013;26:1004-27 CrossRef Medline

4. Brix G, Zwick S, Kiessling F, et al. Pharmacokinetic analysis of tissue microcirculation using nested models: multimodel inference and parameter identifiability. Med Phys 2009;36:2923-33 CrossRef Medline

$$
\begin{array}{r}
\text { (1)A. Lecler } \\
\text { OJ.C. Sadik } \\
\text { IJ. Savatovsky } \\
\text { Fondation Ophtalmologique Adolphe de Rothschild } \\
\text { Paris, France }
\end{array}
$$

